\title{
Incremental development \& revolutions of E-learning software systems in education sector: a case study approach
}

\author{
Varun Gupta ${ }^{*}$, Durg Singh Chauhan ${ }^{1}$ and Kamlesh Dutta ${ }^{2}$
}

\author{
* Correspondence: \\ varun13_cse@yahoo.co.in \\ ${ }^{1}$ Uttarakhand Technical University, \\ Dehradun, Uttarakhand, India \\ Full list of author information is \\ available at the end of the article
}

\begin{abstract}
Advancement in the area of software engineering, mobile computing together with web technologies have paved way for myriad range of applications, including good quality E-learning software's, delivering online classes in real time to unlimited number of students across the world, on a personalized E-learning space for every student. These E-learning software systems have virtually made the whole world as a single campus education hub. However, development of these software's has been a challenge for industry, as the requirement of various stakeholders-learner, educator, institutional management, accreditation bodies, has to be handled in the software effectively. Software systems developed for E-learning applications should implement all the requirements of its diverse stakeholders and must be delivered well in time. Delays, incomplete software and faulty modules could be a big failure for educational institute. To be able to deliver the software within deadline, software's are delivered in increments. In order to support incremental delivery, paper proposes a new requirement prioritization method that selects those requirements for implementation that are essentially required by stakeholders and has a lower regression count associated with them, thereby reducing regression testing effort. This paper reports the advantages reaped from E-learning software project of "Virtual Classroom" employed in teaching "Multimedia Technologies" course to undergraduate students of sixth semester. Total 50 students, enrolled under both distance education and full time education (25 in each category), were asked a set of questions. Results indicate that E-learning system would bring revolution in the field of education, whether study program is full time, part time or a distance education program. Students found augmenting classroom teaching with the use of E-learning software systems as an enriching experience.
\end{abstract}

Keywords: E-learning software system, Virtual classroom, Requirement prioritization, Regression testing, Analytical Hierarchical Process (AHP)

\section{Introduction}

Research in the area of software engineering had been focussed on improving quality of developed software. The software solves problem of the particular application area like medicine, education, engineering etc. Numerous software's finds their application in almost all areas (eg. Microsoft office) and are generic in nature. Others are specific for a given domain (eg. Moodle in education sector, and NS2 for network simulation). Higher quality software will improve quality and efficiency of work to be carried out in

(c) 2013 Gupta et al.; licensee BioMed Central Ltd. This is an Open Access article distributed under the terms of the Creative Commons Attribution License (http://creativecommons.org/licenses/by/2.0), which permits unrestricted use, distribution, and reproduction in any medium, provided the original work is properly cited. 
particular application area. Adoption of software engineering practices during the software development phases can improve the quality of the software, eventually improving the acceptability of software by the users. This paper focuses on the applicability of web 2.0 software applications in education sectors, reports advantages of the introduction of E-learning software, based on authors' teaching experience and presents the solution to various problems that tend to occur during the development of software for education sector.

Education sector requires software in minimum possible time. Delays in delivery of software might not be acceptable to various education organizations. Moreover, misinterpreted, missing or incomplete requirements elicited during the requirement engineering process might result in all activities of education institutes ending up with errors and disorders. For example, if a software development organization delays delivery of software by one year, then it means that client educational institute might be deprived of the benefits of the software for the whole academic year. Another scenario of virtual classroom where one of the requirement in present "copy-paste" environment is "Software must be able to detect the percentage of plagiarism and must report the details" is required essentially by the institute. If software developer is unable to implement this requirement, then all implemented requirements might be at stake, since teacher might wish to evaluate students at various stages in academic year by detecting plagiarism.

In order to avoid delays, software developers try to develop software incrementally by implementing requirements of highest priority. Highest priority requirements are such that they are preferred most by all the stakeholders, and stakeholders will get maximum benefits with the implementation of a highest priority subset of set of thousands of requirements. Effective prioritization of requirements will depend on the quality of stakeholders involved and effectiveness in creating win-win situation among them. Thus, for the education sector, to take advantages of various software's, the software should be of high quality delivered, well in time implementing highest priority requirements.

Once the software with highest priority requirements are delivered and new version or increment requirements are added in existing source code, ripple effects are likely to exist in other code parts. It means that other requirements that were working perfectly well before the additions to the code would now malfunction. Regression testing is the only option to not only check the newly added code but also to check already test code. This calls for investing of more efforts, thereby enhancing cost of software and delaying its delivery to its educational organizations. As discussed earlier, such delays could prove to be very detrimental for such organizations. In order to reduce regression testing, prioritization process could be altered in such a manner that maximum requirements dependent on each other are implemented during the same the same increment. Thus, implementation of next increment would have less chance of creating ripple effects. As a heuristic, requirements with highest regression count and lesser customer satisfaction value could be ignored to achieve more optimizations in regression testing effort. Customer satisfaction is the most important aspect during prioritization. E-learning educational software would find its great acceptability among teachers, students etc., if and only if the needs of these stakeholders are satisfied.

Since, not all of the gathered requirements are equally required by stakeholders, incremental development is possible for E-learning software. Some set of requirements are not mandatory in nature and does not affect the academic work. For example, if 
delivery deadline is very tight, requirements like video conferencing, searching using multiple inputs etc., that require huge implementation efforts could be dropped. Academic work will not suffer due to dropping of these requirements, since all basic requirements related to uploading; downloading of lecture notes and assignments, online tests, automatic generation of results etc. would be implemented in the first release.

E-learning software systems are beneficial not only for students registered as full time programme, but also to those who undertake the course under the category of distance education. In most populated developing country like India, where educating masses is quite challenging and important for having all round development and strong economy, distance education could play a vital role. Distance education in India was adopted as a result of recommendations of the Planning Commission of India (1960) (Third Five Year Plan) and Education Commission, also known as Kothari commission (1964-66) [1]. Some policies like National Policy on Education (1968) were formulated on the basis of recommendations of above commissions. Today, the distance education imparted by numerous universities had been able to cater to the needs of large number of Indian population.

The paper is structured as follows: The need for timely delivery of high quality software to be used in the educational domain for both full time and distance education programmes is highlighted in the introductory section. The existing work related to Elearning and the relevance of requirement prioritization and regression testing is reported in the "related work" section. Efforts are made to get an insight into the area of E-learning tools, techniques and status in countries like India. To improve the quality of such systems, requirement prioritization and regression testing approaches are analyzed, since timely deliveries of high quality E-learning systems can be obtained by following incremental development model. Section "E-Learning Software Systems" describes E-learning software systems from an implementation point of view. Next section "Web 2.0 Applications in Educational Sector" gives the applicability of such systems in educational institutions. It highlights the transformation of implementation model given in the previous section into a set of services offered to the institutes. Section "Survey of Applicability of E-Learning Software In Education Sector: A Case Study" gives the survey conducted by means of questionnaire administered to students registered in full time and distance education mode as experimental subjects. The results are analyzed and discussed in detail in "Result Analysis" section. Section "Proposed Prioritization Model: Development of E-learning software system" gives the proposal for a new requirement prioritization model termed as "CCR" technique where First $\mathrm{C}$ stands for Customer satisfaction, second $\mathrm{C}$ stands for cost and $\mathrm{R}$ stand for Regression count. This model stresses on selection of those requirements that provides maximum customer satisfaction to its intended users (one of the important criteria for educational sector software success) and lowest cost and highest regression count value. The final section "Conclusion and Future Work" summarizes conclusions and highlights future direction.

\section{Related work}

Survey of various E-learning tools and technologies is presented in [2]. Few of the IT organizations involved in building E-learning projects like SAP and Tata Interactive Systems (TIS), are also reported in [2]. 
The use of software agents to enhance the effectiveness of E-learning systems is proposed in [3]. The agents include Personalization agents, Evaluation agents, Query management agents, Feedback agents etc. The agents based E-learning software system was also implemented in the Java Agent Development Environment (JADE) and employed for OOPS training. The agents interact with each other to make E-learning as interactive as possible.

Paper [4] reported current status of E-learning based educational programmes in India. Authors reported that there is a huge increase in the number of educational institutes, Indian universities and the number of students enrolled in various programmes in these educational universities or institutes. These numbers are expected to increase in the near future and thus resulting in burden on existing available resources. Elearning will provide a good solution to the problem of an increase in the number under resource constrained environments, with reputed institutes like Indian Institute of Management Ahmadabad (IIMA), Symbiosis Center for Health Care (SCHC) and AMRITA already started offering some of educational programmes through E-learning.

Web based framework supported by requirement prioritization method that considers the preferences of multiple stakeholders, was proposed in [5]. The proposed prioritization technique is based on the idea of identification of "prioritization required factors" and "reducing factors". Cost and penalty were identified as reducing factors while Benefits, value, Risk, Time to Market and dependencies are categorized as prioritization required factors. Values allotted by each stakeholder for each requirement against each one, among five decision aspects were populated in Prioritization matrix. Each requirement is considered individually one by one decision aspect wise, where preference values are multiplied by weight of stakeholders that had allotted the value and finally added to the product of weight and preference of another stakeholder. Values allotted to each "prioritization required factors" were divided by those allotted to each "reducing factors". The computed value represents final priority value. This technique finds its greatest usage in globally distributed software development environments due to the proposed web based frameworks and such frameworks overcomes global distances that exists between the different software development site teams [6].

Paper [7] reported direct influence of decision aspect prioritization on requirement prioritization and hence on regression testing. In order to analyze the impacts, regression testing technique as proposed in [8] was slightly modified into two versions. First version involves all the algorithmic steps of original version excluding clustering, while later version employs all steps of the proposed algorithm. The two versions were executed on unsuccessful and successful project of the payroll management system. This project was experimental unit. Requirement prioritization and regression testing were experimental variables. To report the dependency between these experimental variables, decision aspect prioritization technique as proposed in [9] and requirement prioritization process as proposed in [5] were employed on the experimental unit. The main findings of the paper were that effectiveness in decision aspect prioritization will bring improvement in a requirement prioritization process, which reduces the number of regression test cases, without decreasing the fault detection capability.

In the present paper, we focus on the advantages and the revolution that could be brought in the education sector, as a result of the introduction of E-learning system. 
The quality of such software systems is of prime importance, since quality of the software determines quality of the imparted and derived knowledge, thereby influencing future of both students and country.

\section{E-learning software systems}

E-learning is defined as an instruction, delivered via a computer that is intended to promote learning [10]. In other words, educational material in the form of multimedia documents (combination of audio, video and text) is delivered with the help of internet, intranet, CD-ROM etc. to various learners. A very good example is of "National Programme on Technology Enhanced Learning (NPTEL)" an Initiative of Ministry of Human resource and development (MHRD) for enhancing the quality of engineering education in the country by providing free online courseware (http://www.nptel.iitm.ac.in). NPTEL provides students and teachers lecture notes of renowned professors of institutes like IIT's and IISC in both video and text formats. This delivery of lecture notes, question banks, assignments etc. is through internet. The CD's of video slides are being sold to students which means delivery if through CD's. Web based E-learning software systems typically involve a dynamic website (web pages whose contents change in accordance with user selections or inputs), a database for storing references to lecture notes (both videos and texts), assignments, and question banks etc., connected through the network to the client computing node. Client computing nodes have a browser that executes the HTML file returned from the server and shows required lectures notes etc. Such a dynamic website is implemented in languages like PHP, active server pages (ASP) etc. Such web page contains the necessary code for accessing (reading, writing etc.) database, transforming user requests into E-learning services etc. With the advancement in web technologies and transition of web from 1.0 to 4.0, most of E-learning software systems are web 2.0 applications, since education delivery through web applications is easier and provides $24 \times 7$ accesses.

\section{Web 2.0 applications in educational sector}

With the advancement in web technologies, very complex web 2.0 applications had emerged. Such web 2.0 applications are installed on educational organization server and assessed world wise (Internet) or within campus only (Intranet) by using browsers at client side. Web 2.0 applications include all social networking sites like Orkut, Facebook, twitter, yahoo, gmail and tools like Moodle, wiki etc.

Such web 2.0 applications like virtual classroom, Moodle etc. automates various academic activities of educational institutes in following manner:

- Students are allowed to see their daily assignments, sample question papers, model test papers, test marks, grades, announcements etc.

- Students are allowed to submit assignments, take online open book test quiz etc.

- Teachers can upload new questions, assignments, grades, marks, comments, announcements, lecture notes (in various formats), research papers etc.

- Teachers can detect plagiarism among student's assignments and with internet resources.

- Teachers can upload e-books etc. 
- It is possible for a renowned expert from distance remote institute to deliver and interact with students using two way audio-visual communication i.e. Video conferencing.

- Students and teachers can post solutions to problems asked by maximum students so that similar problems could be solved reusing solutions of similar problems.

- Students and teachers could interact with each other during non office hours and thus take benefit of virtual classes.

\section{Survey of applicability of E-learning software in education sector: a case study}

E-learning software systems could be a boom for both full time and distance mode education. In developing and populated countries like India building strong economy is one of prime interest activity. For sound economy, education is one of main parameter. Education involves both full time and distance mode educations. One of the objectives of any government is to improve the quality of education, and enhance all round development of the country. E-learning software system would be an asset for any educational organization, achieving this objective. This section presents results of the survey conducted using questionnaire among both distance and full time programme students. For full time education, only B. Tech students were employed for this experimentation, while for Distance education, views of students enrolled in both distance and full time programme students were collected.

\section{Applicability of E-learning software in distance education}

The applicability E-learning systems in distance education, is analysed by administering questionnaire to 25 students enrolled under distance education and equal number of full time students (total 50 Students). Students were asked two questions:

- Introduction of E-learning system would improve the quality of education.

- The E-learning system would make distance education nearly similar to full time education.

Figures 1 and 2 give the results of the questionnaire send to various students to get answers to the questions being asked.

Figure 1 shows that majority of students think that the introduction of an Elearning system would improve the quality of Distance and full time education. Figure 2 shows that maximum students agreed to the fact that introduction of an E-learning system would make distance education almost similar to full time education. After the analysis of these results, some of the students were asked, why they thinks so? Most of them thought that in distance education, there is less collaboration between students due to less interaction among them and learning revolves around the study material. They were of the opinion that there is little interaction with the counsellor. Students were of the opinion that the E-learning system would make problem solving an interactive collaborative session. Further, such systems would allow them to attend live lectures which would result in matching the full time education. 


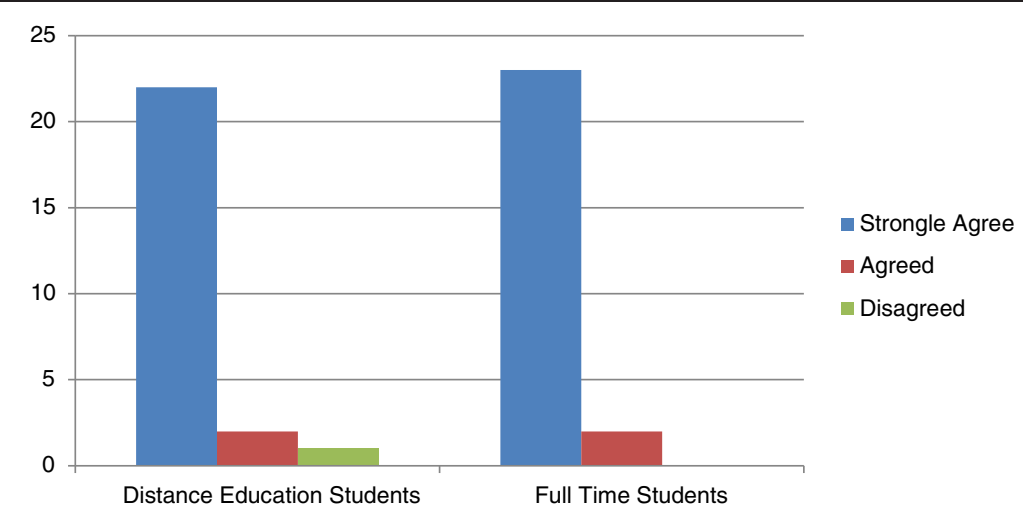

Figure 1 Number of students that think that E-learning would improve quality of education.

\section{Applicability of E-learning software in full time education}

To analyze the applicability of such systems, in full time education, the project of "Virtual Classroom" was uploaded on Intranet, for use by B. Tech third year students of the sixth semester. The project aimed at implementing the activities given in Section "Web 2.0 Applications in Educational Sector" (except fewer ones like Video Conferencing etc.). The software tool was implemented in Hyper Text Preprocessor (PHP), Hyper Text Markup language (HTML), Javascript and MySQL technologies. Students were taught "Software Engineering (SE)" without any virtual classroom tool in previous fifth semester. At the end of the sixth semester, total 35 students studying "Multimedia Technologies (MT)" were given questionnaire using GoogleDocs. The scale of 1 to 5 was used, where 5 means higher value and 1 means lower value to question asked. Following were questions asked in the questionnaire:

- Out of "SE" and "MT", which subject do you find interesting?

- Out of the two subjects, which one you consider best for your future research?

- Out of the two subjects, which one really transformed the hidden ideas of mind into practice?

- Out of the two subjects, which one was the highest scoring for you?

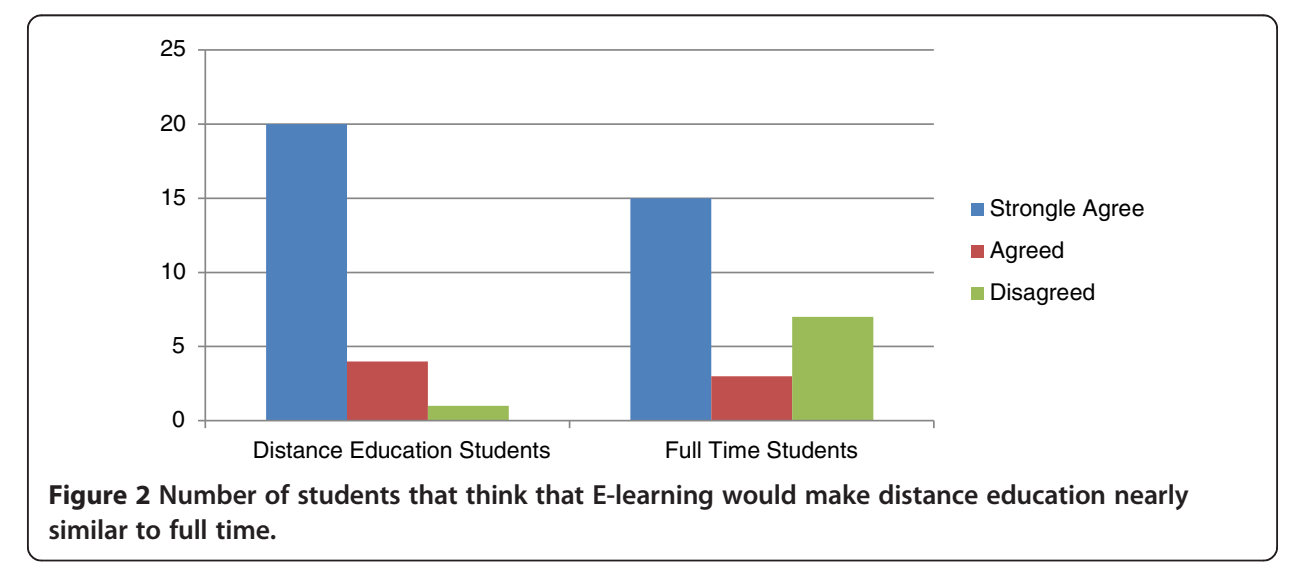


- When compared the teaching strategy for the two subjects, how much you rate these components:

- Easiness.

- Problem solution oriented.

- Collaborative.

- Work Originality due to plagiarism.

- Practice oriented.

- Transparency.

The response given by students to the above mentioned questions is given in Figures 3, 4, 5, 6 and 7. The analysis of responses i.e. values allotted for each question by the students highlights the importance of E-learning systems. Such system improves the quality of teaching and not only makes students academically better but also paves the path for future research.

In Figures 3, 4, 5 and 6, only the number of students who rated using values of 5, 4, 3,2 and 1 are presented graphically. In Figure 7, the ratings of each student for each strategy for two courses are added and presented in the form of graphical representation. Thus, it shows the number of students, categorized in accordance with the value supplied, while Figure 7 presents aggregated allotted values.

\section{Result analysis}

Figure 3 show that students found the course of MT very interesting. When asked the reason behind such results, the majority of students reported that due to virtual classroom they got enough time in classrooms, focussing on what is being taught, without any stress of documentation of classroom notes, since they are available of the intranet. Thus, the whole effort is just to listen, comprehend, understand and documentation of important points. Deadline for assignment submission, plagiarism detection, and support for collaboration among students and teachers, due to chat and posting about problems, and solutions, made everyone come forward and perform, required activities within deadline. Since, software does not accept any assignments after the deadline and due to plagiarism detection capability; students were forced to write after a full

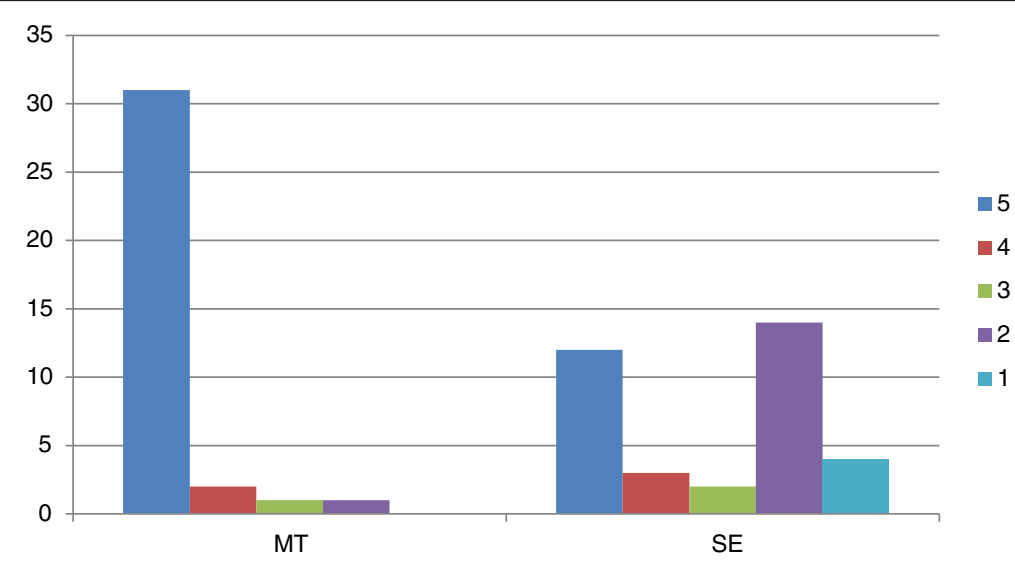

Figure 3 Number of students interested in "MT" and "SE"courses. 


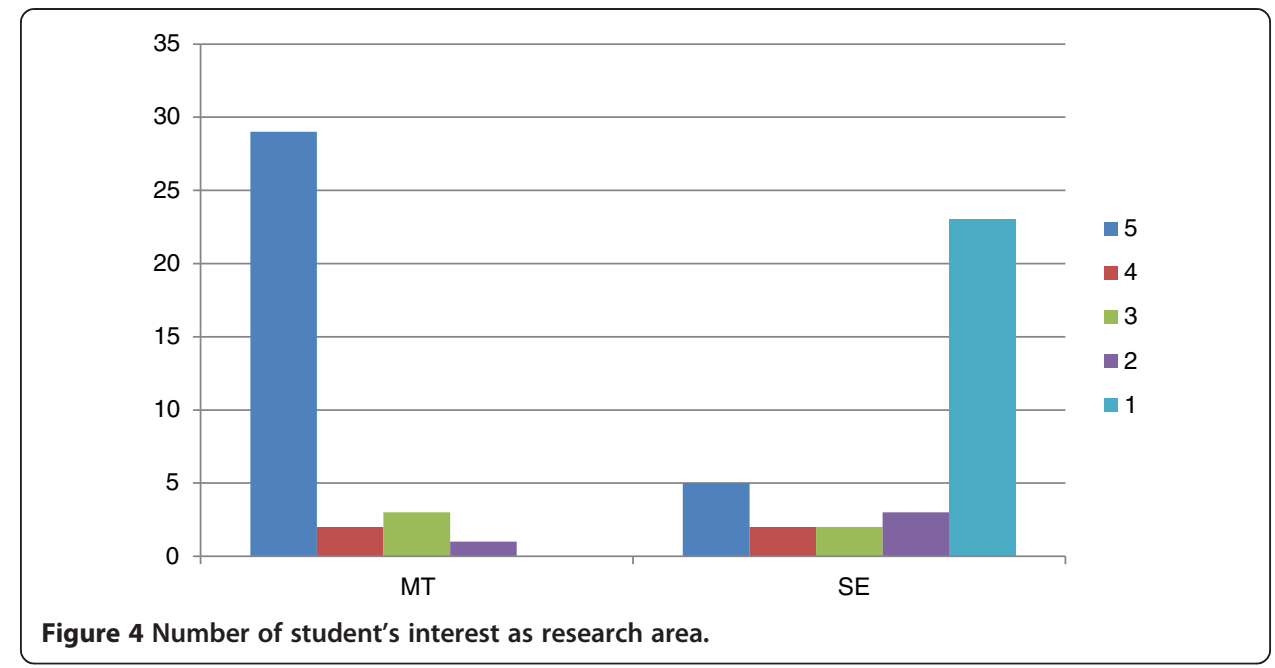

understanding of the application based assignments questions. This allowed them to clear their doubts within a reasonable amount of time, rather than during exam times. Availability of online resources enhanced interest of students, and they were able to work on the problems which required the knowledge and understanding gained during learning processes. Most of the students found problems interesting enough and subsequently expressed their willingness to take up the topics for future research work.

The subject of Multimedia Technologies turned out to be a high scoring subject for students which they passed with very good score. Students found that it is very easy to share problems, find solutions by working collaboratively. Also students were forced to do away the practice of "copy and paste" involved in their daily academic work. Students also reported that use of such tools offers transparency in grades allotment, and overall learning of new subject becomes an easy activity.

In case of the Software Engineering course, since some of the students had applied software engineering knowledge in the implementation of projects, some of these students were also interested in this course. Due to this, few values were also assigned to the various aspects in Figures 3, 4, 5, 6 and 7 but yet these allotted values are far lesser than allotted to "MT" course.

Teaching should be dynamic, means teaching contents must be in consonance with the current research trends. For students, to be able to understand recent research trends, complete basic knowledge and interest in the subject is essential for students.

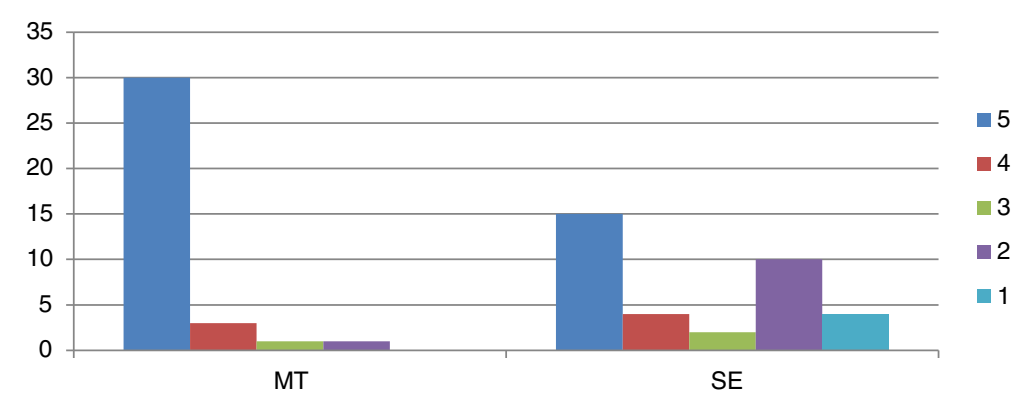

Figure 5 Number of students who transformed ideas into practice. 


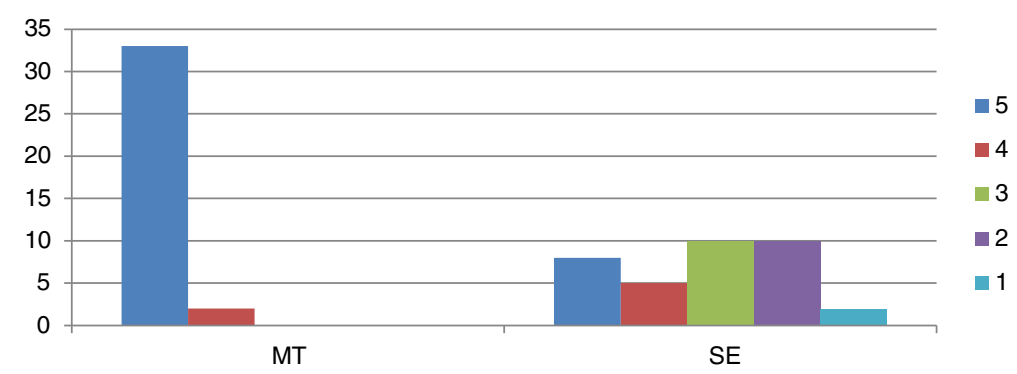

Figure 6 Number of students who find the subject as highest scoring.

Use of E-learning tools, like virtual classroom, made it possible to encourage students to learn while doing the things. Such web 2.0 tools provide $24 \times 7$ access worldwide, and hence irrespective of location of tutor or learner, collaboration could be promoted to solve new problems.

From the presented data, it could be easily concluded that effective teaching, and hence a revolution in the area of education sector could be attributable not only to the quality of teachers, quality of notes etc., but also to quality of software employed for the purpose of E-learning. Quality of E-learning software is the main factor in determining the effectiveness of teaching strategy, since quality software can bring revolution in the education sector. This enhances the quality of learning and knowledge among students and teachers, thereby influencing learners and educators of the next generation.

\section{Proposed prioritization model: development of E-learning software system}

As discussed in previous sections, for effective teaching, E-learning software system should be employed. E-learning modules could either be uploaded on the Internet or on the Intranet. Such E-learning systems are mostly web 2.0 applications that are read/ write and execute web applications.

The poor quality of such applications would mean complete rejection in the education sector. Effective requirement prioritization should be employed so that the highest priority requirements are implemented in resource constrained environment by satisfying diverse stakeholders and reducing the regression testing efforts during later increments.

In order to support incremental delivery, paper proposes a new requirement prioritization method that selects those requirements for implementation that are required at most, by stakeholders and has a lower regression count, associated with them, thereby reducing regression testing effort. The priority of a requirement is determined by "Customer Satisfaction" and "Regression Count Value", such that the cost of implementation of the selected requirement set is approximately within the allotted budgets.

Figure 8 gives the proposed technique for requirement prioritization. The proposal gives a prioritization method that not only considers the decision aspects like customer satisfaction and cost but also takes into consideration regression testing efforts. The objective is to customers; reduce development cost and also reducing the future regression testing efforts.

The calculation of priority against customer satisfaction and cost is almost similar to cost value approach as proposed in [11]. 


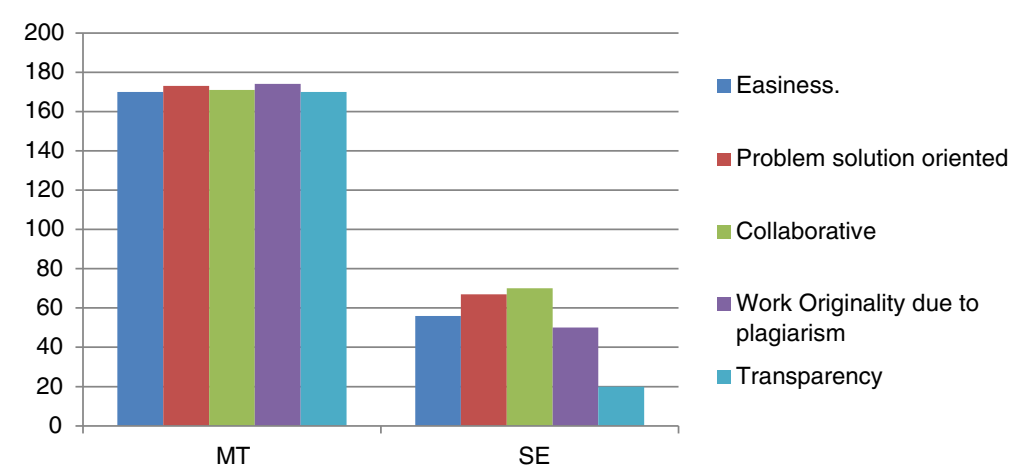

Figure 7 Ratings of individual components of effective teaching strategy.

The working of this proposed prioritization technique is given in form of algorithm in Table 1.

This algorithm generates the set of requirements for implementation. Selected requirements are such that they provide maximum customer satisfaction to its intended users (one of the important criteria for educational sector software success) and lowest cost and highest regression count value. Requirements that provide less value to its customers and have the highest value of regression count are simple ignored since these requirements could never alter project success chances.

The proposed prioritization technique could be named as "CCR" technique where First C stands for Customer satisfaction, second C stands for cost and R stand for Regression count.

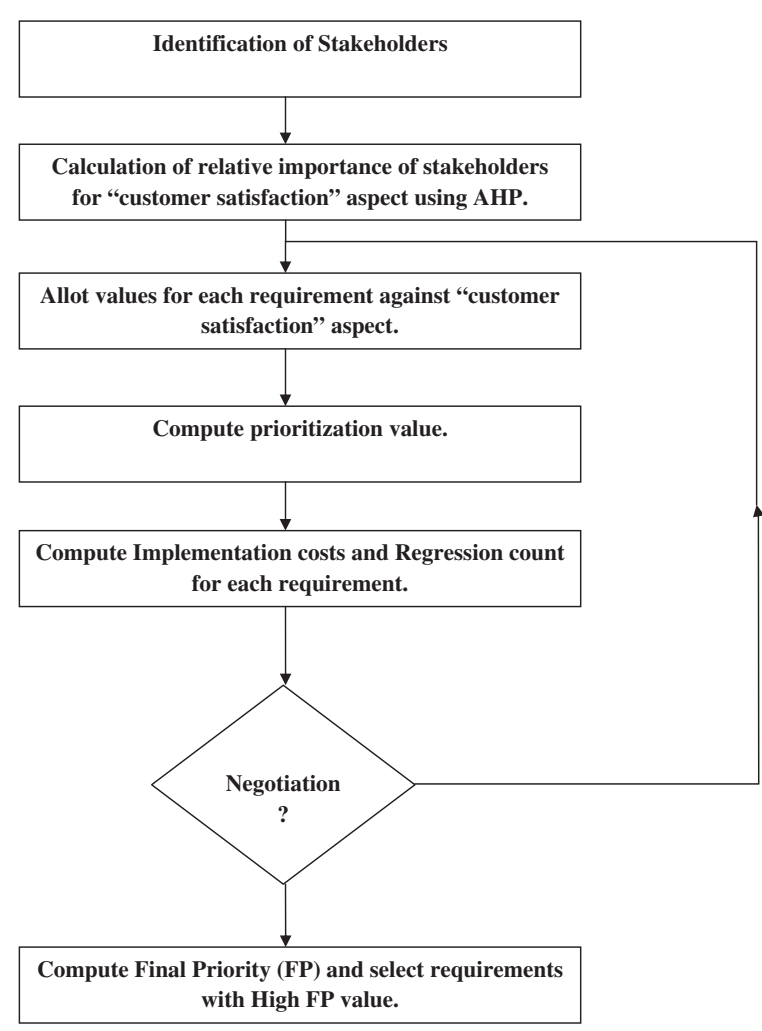

Figure 8 Proposed requirement prioritization model. 
Table 1 Algorithm: requirement prioritization of E-Learning software system

\begin{tabular}{cl}
$\begin{array}{c}\text { Step } \\
\text { number }\end{array}$ & Executable steps \\
\hline $\mathbf{1 .}$ & $\begin{array}{l}\text { Identify influential stakeholders for prioritizing requirements. As a customers or users, a good } \\
\text { combination of experienced teachers, research scholars, students, project staff etc. should be } \\
\text { identified. Teachers could better identify those requirements that are very important for them } \\
\text { and without which their work will suffer. }\end{array}$
\end{tabular}

2. Compute the relative importance of each stakeholder against "customer satisfaction" aspect using Analytical Hierarchical Process (AHP). AHP is a decision making process that allows stakeholders to fill prioritization matrix using a scale of 1-9. The relative prioritization value is then computed and the results are analyzed for accuracy purpose by calculating a consistency index $(\mathrm{Cl})$. A result of execution of this step is computation of the importance of one stakeholder with respect to another. Execution of this step is necessary since experienced teachers should be given higher importance as compared to other stakeholders and voice of students or other project staff with huge development experiences could not be bypassed.

3. For each requirement against customer satisfaction aspect. Each stakeholder allots value using a scale of 1-9 as proposed in [12].

4. $\quad$ Compute the priority using equation 1 :

Priority $=(W a * V a)+(W b * V b)++(W b * V b)(1)$

Wi denotes the relative importance of stakeholder " $\mathrm{i}$ " and $\mathrm{Vi}$ is the value assigned by stakeholder "i". Computation of this step is similar to that in [5].

5. Compute Implementation costs and Regression count for each requirement. This step requires the involvement of software engineers rather than involving customers and users. The implementation of each requirement would be dependent on the implementation of another requirement. Such dependency implies that changes in particular requirement would create ripple effects in other parts of source code i.e. in source code of dependent requirement. This paper terms number of such dependencies between code parts of one requirement and parts of another one as regression count. To compute regression count, developers use AHP technique, where each requirement is pair wise compared with another. If there is very strong dependency between the two requirements say $\mathrm{Ri}$ and $\mathrm{R}_{\mathrm{i}}$, prioritization matrix cell $(\mathrm{i}, \mathrm{j}$ ) is given a value of 9 (scale of 1-9) and for no dependency it is given a value of 1 . Finally the relative regression count value is computed. Similar scale is used to represent the implementation cost of each requirement.

6. Select the highest priority requirement. Such requirements are those that have the highest value of Customers Satisfaction. Denote this set by R'. It varies from organization to organization to have threshold value of the selection. An optimal value could be at least $65 \%$. Requirements with highest regression count and lower development costs are highly desirable. Let $\mathrm{R}$ be the set of gathered requirements. Let $R^{\prime \prime}=R-R^{\prime}$. Each requirement of $R^{\prime \prime}$ is represented by three tuples i.e. $(P, C, R)$

where $\mathrm{P}$ represents assigned priority, $\mathrm{C}$ is development cost and $\mathrm{R}$ is regression count.

-Compute cost associated with the set R'. If it exceeds the allotted budget, perform negotiation by holding talks with stakeholders and re allotment of values and thus repeating step 3 and onwards.

-Sort the requirements in decreasing order of their priorities. Find the set $R^{\prime \prime \prime}$ where, $R^{\prime \prime \prime}=R^{\prime \prime}-R_{(i)}$. The set $R_{(i)}$ denotes the set of those requirements of set $R^{\prime \prime}$ which are having the highest value of $R$ and lowest value of $P$.

•For remaining requirements belonging to set $\mathrm{R}^{\prime \prime \prime}$, compute the final value of priority using equation 2 :

$E P=\left(p^{*} R\right) / C(2)$

In this equation, value is " $\mathrm{C}$ " is not in monetary terms but in terms of scale of 1-9. Thus the highest cost value 9 represents a high cost requirement.

7. Implement the set $\mathrm{R}^{\prime}$ and select requirements of set $\mathrm{R}^{\prime \prime \prime}$ with the highest value of FP until resources permits.

Input: Set of gathered requirements.

Output: Prioritized set of requirements.

\section{Conclusion and future work}

The objectives of this paper were twofold i.e. main objective involves accessing the applicability of E-learning software system in the education sector and another is to propose a method to incrementally develop high quality E-learning system such that it could be an asset to education organization. Such a system will be delivered without 
any delay with almost all preferences of diverse stakeholders implemented in a resource constrained environment.

To achieve the first objective, "Virtual Classroom" E-learning software was employed for teaching a course of "Multimedia Technologies" to the B. Tech students of sixth semester. As compared to courses taught in the fifth semester, students found that they were very comfortable with the course taught using E-learning software system. Such E-learning system provides necessary virtual classroom environment that strengthens classroom face to face in person teaching. Results indicate that students found the use of such E-learning software system as a good database of lecture notes documentation, forces them to collaboratively focus on problems identified by classmates, report unique and original contents, work or findings in assignments. Students also reported that use of such tools provides transparency in grades allotment, and overall learning of new subject becomes an easy activity. E-Learning experience enlightened them with the necessary knowledge of the subject which they were able to transform into practical and thus enabled students to identify topics for future research.

In total 50 students, enrolled under both distance education and full time education (25 in each category) were asked a set of questions and results indicate that E-learning system would bring revolution in the field of education whether study programme is full time, part time or distance education programme.

Educational institutes demands complex E-learning software system. The timely delivery of these systems happens to be a very difficult task. To have timely delivery, paper requirement prioritization technique that prioritizes software requirements are proposed. These requirements provide maximum satisfaction to its customers and lessen regression testing effort. To achieve improved optimizations in regression testing effort, as a heuristic, requirements with highest regression count and lesser customer satisfaction value could be ignored.

The proposed requirement prioritization model needs to be evaluated on live projects and in near future it is expected that the impact of E-learning software system (developed using the proposed model) on educational quality in countries like India, could be evaluated.

Quality of developed E-learning system would influence the quality of teaching in educational sectors, and would useful for educators and learners, both. Country would be benefitted, since economic development depends heavily on education and quality of researchers involved in research projects in the country. E-learning systems overcome the global distances that exist between experts and learners and thereby making the whole world as an education hub.

Thus, it is expected that good quality of E-learning software systems would be developed using the proposed prioritization technique. It is also expected that Mobile compatible E-learning systems would be launched soon so that "any time and any place" access could be provided (M-Learning). Advancement in the area of Software engineering, Mobile Communications and Web Technologies would improve quality of Elearning and hence teaching quality.

Competing interests

The authors declare that they have no competing interests. 


\section{Acknowledgements}

The work as mentioned in the paper would not have been possible without the active involvement of the students. The efforts on the part of the full time, distance education and B.Tech students are acknowledged with reverential thanks.

\section{Author details}

${ }^{1}$ Uttarakhand Technical University, Dehradun, Uttarakhand, India. ${ }^{2}$ Department of CSE, National Institute of Technology, Hamirpur, India.

Received: 15 August 2012 Accepted: 29 April 2013

Published: 10 May 2013

\section{References}

1. Sujatha K (2002) Distance Education at Secondary Level in India: The national open school. Report for the UNESCO International Institute for Educational Planning. http://unesdoc.unesco.org/images/0012/001262/126210e.pdf

2. Ramshirish M, Singh P (2006) E-learning: Tools and Technology. DRTC Conference on ICT for Digital Learning Environment, Banglore

3. Sivakumar N, Vivekanandan K, Arthi B, Sandhya S, Katta V (2011) Incorporating agent technology for enhancing the effectiveness of E-learning system. Int J Comput Sci Issues (IJCSI) 8(3):454-460

4. Rajpal S, Singh S, Bhardwaj A, Mittal A (2008) E-Learning Revolution: Status of Educational Programs in India. Vol 1 . International Multi Conference of Engineers and Computer Scientists, Hong Kong, pp 846-851

5. Gupta V, Srivastav M (2011a) Web based tool supported requirement prioritization: based on multiple stakeholder preferences. Int J Comput Eng Inf Technol (IJCEIT) 25(1):12-19

6. Gupta V, Srivastav M (2011 b) Overcoming global distance in globally distributed developments by Web based framework. CiiT Int J Software Eng Technol, June 2011, DOI: SE062011003

7. Gupta V, Chauhan DS, Dutta K (2012b) Impact analysis of requirement prioritization on regression testing. AWER Procedia Inf Technol Comput Sci 2:379-383

8. Gupta V, Chauhan DS (2011c) Hybrid Regression Testing Technique: A Multi Layered Approach. IEEE annual Conference (INDICON), Hyderabad

9. Gupta V, Chauhan DS, Dutta K (2012) Hybrid Decision Aspect Prioritization Technique for Globally Distributed Developments. Vol 38. Procedia Engineering, Elsevier, pp 3614-3627

10. Clark RC, Mayer RE (2003) E-learning and the science of instruction. Jossey-Bass, San Francisco

11. Jim A, Smith RK, David C (2007) Value-Oriented requirements Prioritization in a Small Development. IEEE software 24(1):32-37

12. Saaty T (1980) The Analytic Hierarchy Process. McGraw-Hill, New York

doi:10.1186/2192-1962-3-8

Cite this article as: Gupta et al: Incremental development \& revolutions of E-learning software systems in education sector: a case study approach. Human-centric Computing and Information Sciences 2013 3:8.

\section{Submit your next manuscript to BioMed Central and take full advantage of:}

- Convenient online submission

- Thorough peer review

- No space constraints or color figure charges

- Immediate publication on acceptance

- Inclusion in PubMed, CAS, Scopus and Google Scholar

- Research which is freely available for redistribution

Submit your manuscript at www.biomedcentral.com/submit 